\title{
Histone Deposition Proteins: Links between the DNA Replication Machinery and Epigenetic Gene Silencing
}

\author{
A.A. Franco and P.D. Kaufman \\ Lawrence Berkeley National Laboratory and Department of Molecular and Cell Biology, \\ University of California, Berkeley, California 94720
}

The information encoded in all eukaryotic genomes is organized into a nucleoprotein complex called chromatin. Chromatin is essential for compacting genomic DNA and plays a primary role in governing the expression status of genes. Chromatin is a diverse and dynamic polymer whose composition is modulated to build specialized chromosome structures, such as those found at centromeres and telomeres (for review, see Grewal and Moazed 2003). The fundamental repeating unit of chromatin is the nucleosome, containing an octamer of histone proteins, two each of H2A, H2B, H3, and H4, around which 146 bp of DNA wraps 1.7 times. This review will focus on how nucleosomes are assembled by histone chaperones that deposit histones during DNA replication or RNA transcription. We will begin by describing the biophysical properties governing nucleosome formation and the mechanisms of de novo nucleosome formation at sites of DNA synthesis. Then, we will discuss the functional overlap between histone chaperones involved in DNA replication-coupled and replication-independent nucleosome assembly. Finally, we will review recent data demonstrating the role of histone chaperones in the tight temporal coupling of histone deposition and DNA replication.

\section{MOLECULAR MECHANISMS OF NUCLEOSOME ASSEMBLY}

\section{Nucleosome Architecture}

Nucleosome assembly occurs in two steps. First, histones $\mathrm{H} 3$ and $\mathrm{H} 4$ are deposited onto DNA, followed by the addition of histones $\mathrm{H} 2 \mathrm{~A}$ and $\mathrm{H} 2 \mathrm{~B}$ (for review, see Verreault 2000). This order of addition reflects the structure of the nucleosome (Luger et al. 1997) and the biophysical properties of histone subcomplexes (Eickbush and Moudrianakis 1978). In the nucleosome, an (H3/H4) tetramer organizes the central $120 \mathrm{bp}$ of the DNA and is flanked by two histone $\mathrm{H} 2 \mathrm{~A} / \mathrm{H} 2 \mathrm{~B}$ dimers. In the absence of DNA, the histone octamer is stable only when salt concentrations exceed $2 \mathrm{M}$ and the temperature is maintained near $4^{\circ} \mathrm{C}$. At more physiological conditions, histone octamers dissociate into two $\mathrm{H} 2 \mathrm{~A} / \mathrm{H} 2 \mathrm{~B}$ dimers and an $(\mathrm{H} 3 / \mathrm{H} 4)_{2}$ tetramer (Kornberg and Thomas 1974; Eickbush and Moudrianakis 1978). These stable subcomplexes had previously been thought to be the only intermediates in nucleosome formation (for review, see Verreault 2000); as discussed below, this view has been challenged by recent data (Tagami et al. 2004).
The primary forces governing nucleosome formation are electrostatic. Combining pure histones and DNA at physiological salt concentrations results in the formation of insoluble aggregates. However, high concentrations of anionic molecules facilitate in vitro nucleosome formation by shielding the positively charged histones. Indeed, gradual reduction of salt concentration also promotes nucleosome formation because $(\mathrm{H} 3 / \mathrm{H} 4)_{2}$ tetramers associate with DNA more avidly then $\mathrm{H} 2 \mathrm{~A} / \mathrm{H} 2 \mathrm{~B}$ dimers (for review, see Kaufman and Almouzni 2000). Because charge shielding is sufficient to promote nucleosome assembly in vitro, verification of the physiological relevance of biochemically identified histone chaperones has been important. This had previously been most easily achieved in genetically tractable organisms. However, the recent introduction of siRNA techniques has facilitated the study of deposition factors in human cell culture experiments (Hoek and Stillman 2003; Nabatiyan and Krude 2004).

\section{DNA Replication Creates Platforms for Epigenetic Marks}

The deposition of a genome's worth of nucleosomes occurs concomitant with DNA replication during $\mathrm{S}$ phase. To understand how histone chaperones coordinate with the DNA replication machinery we will first review some of the fundamentals of eukaryotic DNA replication. A prominent theme of this discussion will be the cascade of protein-protein interactions that guide the assembly and disassembly of replisome components and thereby order events during DNA replication. This will lead to consideration of how replication proteins regulate epigenetic states.

DNA replication. To dissect eukaryotic DNA synthesis in vitro, biochemists have taken advantage of viral replication systems to circumvent the complexity of cellular origins. Plasmids harboring the Simian Virus 40 (SV40) DNA replication origin are replicated in human cell extracts upon addition of a single virally encoded protein, the SV40 large tumor antigen (T antigen) (for review, see Fanning and Knippers 1992). T antigen is both a DNA sequence-specific replication initiation protein and a DNA helicase. All other factors required for DNA synthesis were isolated from human cell extracts using this assay system (Waga and Stillman 1998). These include the single-stranded binding protein, RPA, which stabilizes unwound DNA during initiation and plays a 
central role in regulating replisome formation (Brill and Stillman 1989). For example, RPA interacts with two other essential components of the replisome, polymerase $\alpha$ (Pol $\alpha)$ primase and the clamp-loading complex Replication Factor C (RFC) (see below).

Most polymerases cannot initiate synthesis de novo. Thus, after DNA unwinding, DNA synthesis begins when the four-subunit DNA Pol $\alpha$ uses both its RNA primase and DNA polymerase activities to synthesize short (35-50-nt) RNA-DNA primers (Murakami et al. 1992). Pol $\alpha$ is recruited to single-stranded DNA via an interaction with RPA (for review, see Waga and Stillman 1998). After primer synthesis, DNA replication elongation proceeds continuously on the leading strand and discontinuously on the lagging strand at each Okazaki fragment. Elongation begins with polymerase switching, which occurs when Pol $\alpha$ is replaced with the more processive DNA polymerase $\delta$ (Pol $\delta$ ) (Tsurimoto and Stillman 1991). Pol $\delta$ processivity is greatly enhanced by association with the accessory factor Proliferating-Cell Nuclear Antigen (PCNA). PCNA is a toroidal homotrimer that encircles DNA, topologically tethering polymerases to the DNA template and thus greatly increasing their processivity. PCNA is therefore referred to as a "clamp" (for review, see Jeruzalmi et al. 2002). The three-dimensional structures, though not the primary sequences, of these clamps are conserved among eubacteria, archaebacteria, bacteriophage T4, and eukaryotes (Jeruzalmi et al. 2002). Besides polymerases, PCNA also binds to a large number of other proteins involved in DNA replication, repair, and modification (for review, see Warbrick 2000). Additionally, PCNA directs a nucleosome assembly protein to replicated DNA templates (see below) (Shibahara and Stillman 1999; Zhang et al. 2000; Krawitz et al. 2002).

The task of topologically loading processivity clamps onto DNA is performed by evolutionarily conserved protein complexes termed "clamp loaders" (for review, see Jeruzalmi et al. 2002). The eukaryotic PCNA-loading complex is RFC, a DNA- and PCNA-stimulated ATPase that loads PCNA onto $3^{\prime} \mathrm{OH}$-primer-template junctions in an ATP-dependent manner. RFC promotes the switch from replication initiation to elongation by competing with Pol $\alpha$ for interaction with RPA at primer-template junctions prior to PCNA loading (Yuzhakov et al. 1999). This polymerase switch need happen only once on the leading strand, but on the lagging strand occurs at every Okazaki fragment (Waga et al. 1994). Once RFC has loaded PCNA onto DNA, Pol $\delta$ binds to PCNA, displacing RFC. Interestingly, RFC may remain associated with the elongating replisome though interactions with Pol $\delta$ and RPA (Yuzhakov et al. 1999). This association would leave RFC available for interaction with factors that regulate DNA replication.

Finally, after elongation, Okazaki fragment maturation occurs. RNA primers are removed by RNase HI and FEN1, the resulting gaps are filled in by the pol $\delta$ replisome, and the DNA fragments are covalently joined by DNA ligase I (for review, see Waga and Stillman 1998). FEN1 and DNA ligase I also bind PCNA, highlighting PCNA's central role in coordinating DNA replication events. Similar coordination of PCNA-mediated events operates during strand resealing associated with DNA repair (for review, see Maga and Hubscher 2003).

Histone deposition during DNA synthesis: Relation to epigenetic marks. Covalent histone modifications, such as methylation, acetylation, and ubiquitination, regulate local chromosome structure and gene expression status (for review, see Jenuwein and Allis 2001). These modifications can function as epigenetic marks defining chromosome regions independent of DNA sequence. The new histones deposited during DNA synthesis are not marked in the same way as the parental histones (RuizCarrillo et al. 1975; Jackson et al. 1976) and thus might erase or dilute existing epigenetic marks. Therefore, a major question regarding replication-linked nucleosome assembly had been the fate of parental nucleosomes after passage of the replication fork. To address this, pulsechase experiments were performed using isotope and density labels to mark parental histones. Upon cross-linking of histones in nucleosomes and separation of labeled species by density gradient sedimentation, two distinct species of nucleosomes were detected. The first contained tetramers of new $\mathrm{H} 3 / \mathrm{H} 4$ molecules in the same nucleosome as two dimers of old $\mathrm{H} 2 \mathrm{~A} / \mathrm{H} 2 \mathrm{~B}$. The second contained tetramers of old $\mathrm{H} 3 / \mathrm{H} 4$ associated with one dimer of new and one dimer of old $\mathrm{H} 2 \mathrm{~A} / \mathrm{H} 2 \mathrm{~B}$ (Jackson 1987). These data are consistent with the structure and biophysical properties of the nucleosome, and suggest that the $(\mathrm{H} 3 / \mathrm{H} 4)_{2}$ tetramers and $\mathrm{H} 2 \mathrm{~A} / \mathrm{H} 2 \mathrm{~B}$ dimers of parental nucleosomes are separately inherited behind the replication fork. Furthermore, $(\mathrm{H} 3 / \mathrm{H} 4)_{2}$ tetramers are segregated to the daughter strands as intact units, while $\mathrm{H} 2 \mathrm{~A} / \mathrm{H} 2 \mathrm{~B}$ dimers randomly reassociated with new and old $(\mathrm{H} 3 / \mathrm{H} 4)_{2}$ tetramers on both daughter strands (Fig. 1) (Jackson 1987, 1990; Gruss et al. 1993). These data are consistent with other experiments demonstrating that incorporation of $\mathrm{H} 3$ and $\mathrm{H} 4$ precedes $\mathrm{H} 2 \mathrm{~A}$ and $\mathrm{H} 2 \mathrm{~B}$ in vivo (Worcel et al. 1978) and in vitro (Smith and Stillman 1991). Intriguingly, recent data suggest that histone chaperones may bind dimers of $\mathrm{H} 3 / \mathrm{H} 4$ instead of tetramers (Tagami et al. 2004) suggesting that two chaperone molecules may act in concert to form new $(\mathrm{H} 3 / \mathrm{H} 4)_{2}$ tetramers.

Notably, models for the lateral spreading of chromatin states easily accommodate interspersed new and parental histones (for review, see Richards and Elgin 2002). These models rely on recent data describing the self-reinforcing nature of epigenetic marks, in which a particular mark recruits the enzymes responsible for generating that mark. For instance, methylation of H3 lysine 9 (H3$\mathrm{K} 9 \mathrm{Me}$ ) is an epigenetic mark recognized by the HP1 protein. HP1, in turn, interacts with the H3 K9 methyltransferase, $\mathrm{Su}$ (var)3-9, thus recruiting the marking enzyme to areas already containing the mark. Additionally, like HP1, Su(var)3-9 contains a conserved chromodomain that contributes to targeting the methyltransferase to heterochromatin via the H3-K9Me mark (Melcher et al. 2000).

Epigenetic marks on histones, then, generally are renewed after DNA replication. However, replication may 


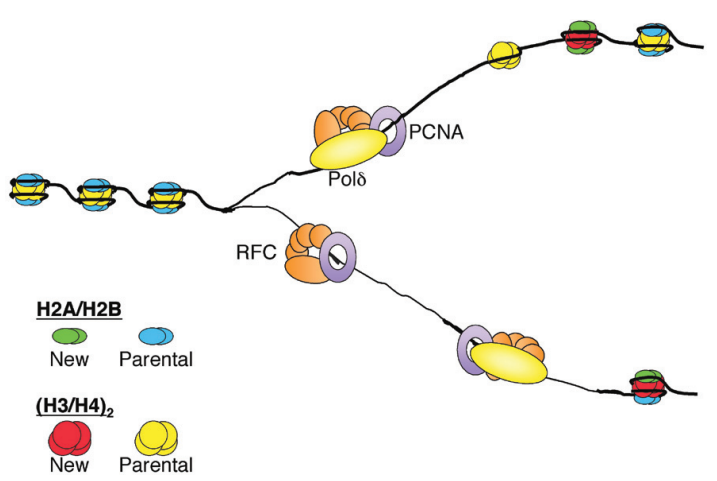

Figure 1. Segregation of histones at replication forks. Nucleosomes are detected within $\sim 250$ bp of the site of DNA synthesis. During fork passage, parental nucleosomes separate into $\mathrm{H} 2 \mathrm{~A} / \mathrm{H} 2 \mathrm{~B}$ dimers (blue) and $(\mathrm{H} 3 / \mathrm{H} 4)_{2}$ tetramers (yellow) that randomly reassociate with newly synthesized histones (red and green) on each daughter strand. DNA synthesis on the leading strand (top) is continuous and accomplished by Pol $\delta$ tethered to the DNA substrate via interaction with the sliding clamp PCNA. On the lagging strand (bottom), RNA/DNA primers synthesized by Pol $\alpha$ are extended by Pol $\delta$ discontinuously. At each Okazaki fragment, a polymerase-switching event catalyzed by the PCNA-loading complex RFC displaces Pol $\alpha$ and recruits Pol $\delta$. RFC may remain associated with the replisome via Pol $\delta$ and the single-strand binding protein RPA (not shown).

provide a window of opportunity where these marks can be erased or altered. Consistent with this idea, mutations in PCNA alter the extent and stability of epigenetic gene silencing in budding yeast (Zhang et al. 2000; Sharp et al. 2001). As discussed below, this role for PCNA has been associated with its interaction with the DNA replicationlinked chromatin assembly factor, CAF-1.

Histone chaperones that function during DNA replication. A variety of data from multiple organisms indicate close coordination between DNA synthesis and histone deposition. Nucleosome formation occurs rapidly following DNA replication in vivo (Worcel et al. 1978; Jackson 1990). Additionally, in both human and yeast cells, histone deposition during $\mathrm{S}$ phase is required for viability (Han et al. 1987; Kim et al. 1988; Nelson et al. 2002; Nabatiyan and Krude 2004), and in human cells concomitant histone deposition is required for completing DNA replication (Hoek and Stillman 2003; Ye et al. 2003).

Several histone chaperones have been implicated in nucleosome assembly at sites of DNA synthesis (Fig. 2). Biochemical experiments designed to isolate replicationcoupled chromatin assembly factors from human cell extracts led to the discovery of Chromatin Assembly Factor1 (CAF-1) (Smith and Stillman 1989). CAF-1 is an evolutionarily conserved heterotrimeric protein complex that binds histones $\mathrm{H} 3 / \mathrm{H} 4$ and delivers them to replicating DNA through an interaction with PCNA (Shibahara and Stillman 1999; Zhang et al. 2000; Krawitz et al. 2002). The biochemical activity and subunit structure of CAF-1 is conserved among yeast, plants, frogs, and flies (Kamakaka et al. 1996; Kaufman et al. 1997; Kaya et al. 2001;

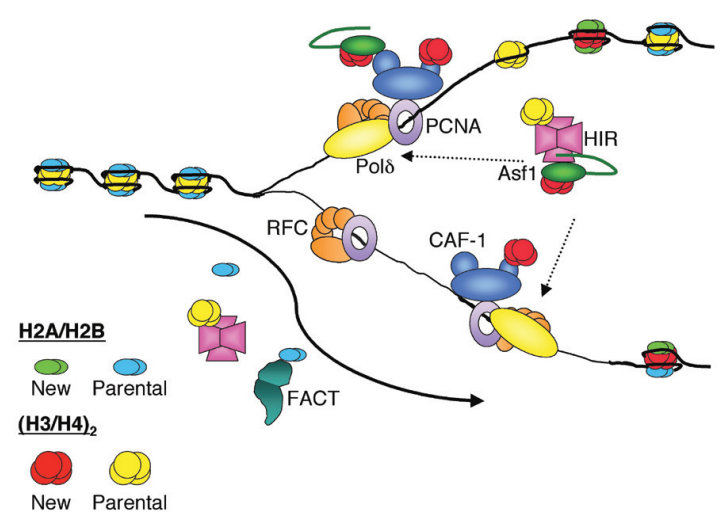

Figure 2. Histone deposition proteins at sites of DNA replication. CAF-1 is recruited to replication forks though an interaction with PCNA. Asf1 and CAF-1 cooperate to deposit newly synthesized histones. However, Asfl and the Hir proteins also contribute to nucleosome formation in a manner independent of CAF-1. Chaperones are also likely to be involved in redepositing parental nucleosomes after replication fork passage. Likely candidates include the FACT complex and the Hir protein complex.

Quivy et al. 2001). In mammalian cells, CAF-1 colocalizes with DNA replication foci during $\mathrm{S}$ phase, and is recruited to sites of DNA repair at other times (Krude 1995; Green and Almouzni 2003), consistent with a function at sites of DNA synthesis. Recent work shows that inactivation of CAF-1 in human cells blocks cell cycle progression via $\mathrm{S}$ phase checkpoint activation (Hoek and Stillman 2003; Ye et al. 2003). Additionally, shutting off histone synthesis during $\mathrm{S}$ phase blocks DNA synthesis in human cells (Nelson et al. 2002; Ye et al. 2003). Together, these data demonstrate a requirement for coordinating nucleosome assembly and DNA replication in human cells. In contrast, in Saccharomyces cerevisiae, DNA replication can be completed in the absence of new histone synthesis, although the resulting chromosomes are unable to segregate and viability is lost (Han et al. 1987; Kim et al. 1988). These data suggest that human cells are more sensitive to perturbation of histone deposition during $\mathrm{S}$ phase.

Data from multiple organisms demonstrate that replication-linked histone deposition contributes to epigenetic control of gene expression. In budding yeast, the genes encoding the $\mathrm{CAF}-1$ subunits $(C A C 1, C A C 2$, and $C A C 3)$ are not essential and are not required for cell cycle progression (Kaufman et al. 1997). However, cells lacking CAF1 are defective in position-dependent gene silencing (Enomoto et al. 1997, 1998; Kaufman et al. 1997; Monson et al. 1997). Likewise, Arabidopsis mutants lacking CAF1 display loss of transcriptional gene silencing and developmental defects in meristematic tissue (Kaya et al. 2001; Takeda et al. 2004). Additionally, human cells overexpressing a dominant-negative fragment of the large subunit of CAF-1 display reduced transcriptional silencing of a reporter gene (Tchenio et al. 2001). Together, these data demonstrate that CAF-1 plays a role in regulating chromatin-mediated transcriptional states, and that this function is conserved throughout eukaryotic organisms. 
However, CAF-1 is not the only route for delivery of histones $\mathrm{H} 3 / \mathrm{H} 4$ to chromatin. In budding yeast, simultaneous disruption of CAF-1 and a second histone chaperone protein complex, the HIR proteins, causes much more severe defects in heterochromatic silencing than observed in cells lacking either complex alone (Kaufman et al. 1998). Additionally, yeast cells lacking both CAF-1 and HIR proteins also have altered centromeric chromatin and impaired kinetochore function (Sharp et al. 2002). Together, these data demonstrate significant functional overlap between CAF-1 and the HIR proteins in budding yeast. There are four HIR genes in yeast (HIR1, HIR2, HIR3, and HPC2) that were identified in genetic screens for factors required for repression of histone gene transcription upon replication arrest (Osley and Lycan 1987; Xu et al. 1992). In humans, a single polypeptide, HIRA, shares homology with both the yeast Hir1 and Hir2 proteins. In budding and fission yeasts and humans, the HIR proteins repress histone transcription outside of S phase (Osley and Lycan 1987; Nelson et al. 2002; Blackwell et al. 2004). Additionally, in vitro studies of human and Xenopus HIRA show that HIRA facilitates replication-independent histone deposition (Ray-Gallet et al. 2002; Tagami et al. 2004). Thus, the HIR proteins are conserved eukaryotic histone deposition factors that supplement CAF-1 function.

In addition to the HIR proteins, Asfl is another conserved histone H3/H4-binding and deposition factor. Asf1 was isolated from Drosophila extracts as a factor that stimulates CAF-1 activity in vitro. Specifically, addition of Asf1 stimulates substoichiometric amounts of CAF-1 to produce more nucleosomes (Tyler et al. 1999). Asf1 proteins from yeast and humans also display this activity (Sharp et al. 2001; Mello et al. 2002). Stimulation of CAF-1 by Asf1 likely is related to the direct interaction between Asf1 and the Cac2/p60 subunit of CAF-1 (Tyler et al. 2001; Krawitz et al. 2002; Mello et al. 2002). Like CAF-1, Asf1 is not essential for viability in $S$. cerevisiae, and deletion of ASF1 does not significantly alter heterochromatic gene silencing. However, Asfl is essential for efficient silencing and cell cycle progression in the absence of CAF-1 (Tyler et al. 1999; Sharp et al. 2001; Sutton et al. 2001). Genetic epistasis experiments demonstrated that Asf1 is required for the HIR protein-mediated silencing pathway, and Asf1 directly binds to HIR proteins (Sharp et al. 2001; Tagami et al. 2004). Additionally, Asf1 becomes essential for CAF-1 activity both in vivo and in vitro when the interaction between CAF1 and PCNA is disrupted (Krawitz et al. 2002). These data suggest that Asf1 provides an alternative mechanism for coupling histone deposition to DNA replication in addition to the PCNA-CAF-1 interaction.

Native protein complexes containing either CAF-1 or Asf1 also contain newly synthesized histones H3 and H4 (Kaufman et al. 1995; Verreault et al. 1996; Tyler et al. 1999) identified by the conserved pattern of acetylation on K5 and K12 of histone H4. These data are consistent with the view that these protein complexes target newly synthesized histones to nascent DNA. However, the functional role for histone acetylation in nucleosome assem- bly is not yet clear. Histone acetylation is not essential for histone deposition by either CAF-1 or Asf1 in vitro (Shibahara et al. 2000; Sharp et al. 2001). Indeed, the histone $\mathrm{H} 3 / \mathrm{H} 4$ amino-termini can be entirely deleted without affecting deposition by CAF-1 (Shibahara et al. 2000). Therefore, the biological role for these modifications may instead be important for transport of newly translated histones into the nucleus. Consistent with this idea, an enzyme complex that performs synthesis-related histone modification has recently been identified in both the cytoplasmic and nuclear compartments (Ai and Parthun 2004; Poveda et al. 2004).

The ability of CAF-1 and Asf1 to assemble histones regardless of acetylation status suggests an additional possibility regarding histone inheritance during DNA replication. Histones in front of replication forks have different modification patterns than do newly synthesized molecules. Therefore, the lack of modification specificity of CAF-1 and Asf1 would allow them to participate in the transient dissociation and redeposition of parental histones during replication fork movement. Development of efficient in vitro systems for the replication of chromatin templates will be required to test for this activity.

\section{Functional Overlap between \\ Replication-coupled and Replication-independent Histone Deposition}

In addition to nucleosome assembly factors that operate during DNA replication, other histone deposition proteins are likely to function during both DNA replication and transcription. Elegant studies recently established the FACT (Facilitates Chromatin Transcription/Transactions) complex as a bona fide histone deposition protein (Belotserkovskaya et al. 2003). FACT binds histone $\mathrm{H} 2 \mathrm{~A} / \mathrm{H} 2 \mathrm{~B}$ dimers, moves them out of the way of elongating RNA polymerase, and subsequently promotes reformation of the nucleosome (Belotserkovskaya et al. 2003; Saunders et al. 2003). Human FACT was isolated based on its ability to promote transcription elongation on a chromatin template in vitro (Orphanides et al. 1998). Additionally, protein components of yeast FACT were isolated as Pol $\alpha$ binding factors (Wittmeyer et al. 1999), and genetic studies in yeast and biochemical studies in Xenopus indicate that FACT facilitates DNA replication as well as transcription (for review, see Formosa 2003).

In budding yeast, the HIR proteins and Asf1 become important for growth in the absence of FACT (Formosa et al. 2002). A simple explanation for these genetic interactions is that the HIR/Asfl proteins, in their capacity as histone chaperones, compensate for defects in FACT-mediated histone deposition (Formosa et al. 2002). Because FACT appears to act during both replication and transcription, these genetic data raise the possibility that the HIR/Asf1 proteins function during both replication-coupled and replication-independent nucleosome assembly (Fig. 3).

The extensive functional overlap between replicationcoupled and replication-independent histone deposition in yeast may also be facilitated by the existence of a sin- 


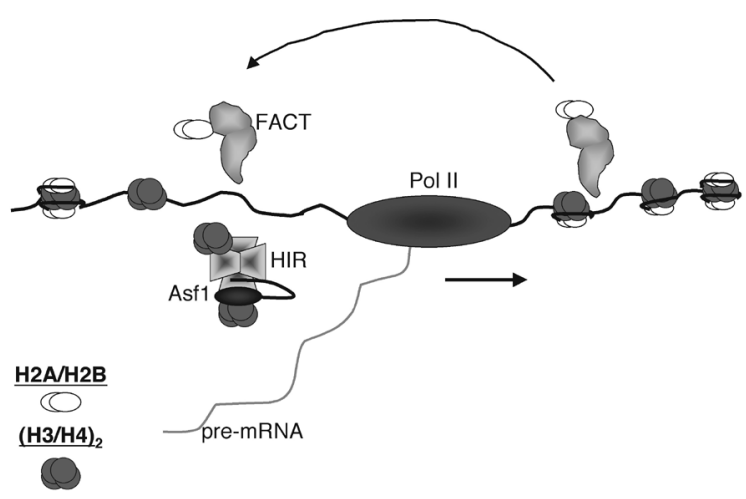

Figure 3. Transcription-coupled histone deposition. RNA transcript elongation requires disruption of nucleosomes ahead of RNA polymerase and reformation of chromatin structure in the wake of the polymerase. FACT performs both of these activities. Additionally, the HIR proteins and Asfl might also assist reformation of nucleosomes in the wake of RNA polymerase.

gle isoform of $\mathrm{H} 3$ in this organism. Histone $\mathrm{H} 3$ in yeast is most closely related to the constitutively expressed H3.3 isoform of higher eukaryotes found in actively transcribed chromatin (Baxevanis and Landsman 1998; Ahmad and Henikoff 2002). In human cells, H3.3 copurifies with HIRA but not CAF-1. Human H3.1, in contrast, is expressed exclusively during $\mathrm{S}$ phase (Franklin and Zweidler 1977), and copurifies with CAF-1 but not HIRA (Tagami et al. 2004). Thus, in humans there appears to be a clear division of labor between CAF-1-mediated replication-coupled and HIRA-mediated replication-independent histone deposition. However, Asf1 is present in both the H3.1- and H3.3-containing complexes. Thus, in both single-celled yeasts and multicellular eukaryotes, replication-linked and replication-independent histone deposition pathways share Asfl as a common factor.

\section{Active Coupling of Histone Deposition DNA Replication}

In vivo, histone deposition and DNA replication are temporally coupled (Worcel et al. 1978; Sogo et al. 1986; Jackson 1990), and inhibition of either CAF-1 or new histone synthesis in human cells inhibits DNA replication (Nelson et al. 2002; Hoek and Stillman 2003; Ye et al. 2003). Why does DNA synthesis halt when histone deposition is disrupted? One possibility is that replication in the absence of chromatin assembly results in DNA damage and activation of checkpoints halts fork movement. Indeed, disruption of CAF-1 activates the DNA Damage/S phase checkpoint (Hoek and Stillman 2003; Ye et al. 2003). Subsequent inactivation of the checkpoint either by the addition of caffeine or inhibition of both the ATM and ATR checkpoint kinases allowed DNA synthesis to proceed, but reduced cell viability (Ye et al. 2003). In yeast, the lethality caused by uncoupling histone and
DNA synthesis cannot be reversed by restoring histone protein synthesis once cells have completed $\mathrm{S}$ phase (Han et al. 1987; Kim et al. 1988). Together, these data suggest that irreparable damage occurs to chromosomes when DNA is synthesized in the absence of concomitant histone deposition.

What kind of signal leads to checkpoint activation in human cells when CAF-1 function is disrupted? Because DNA synthesis continues in the absence of CAF-1 only when the S-phase checkpoint is removed, it is unlikely that lack of histone deposition causes a topological or physical barrier to DNA replication. Rather, we hypothesize that the observed S-phase arrest occurs because replication forks pause or stall in response to CAF-1 depletion, thereby activating the checkpoint. Consistent with this idea, replication forks themselves act as sensors of DNA damage and are required for the activation of the Sphase checkpoint in response to the DNA alkyating agent MMS (Tercero et al. 2003).

What proteins are likely to be involved in this chromatin assembly surveillance mechanism? The most wellstudied mechanism for coupling histone deposition and DNA replication is the physical interaction between CAF-1 and PCNA (Shibahara and Stillman 1999; Sharp et al. 2001; Krawitz et al. 2002). Thus, one possibility is that CAF-1 via PCNA signals to the replisome that histone deposition is occurring. Additionally, the checkpoint kinase, $\operatorname{Rad} 53$, has recently been implicated in regulating nonnucleosomal histone protein degradation (Gunjan and Verreault 2003) and in this capacity may function as a sensor of histone levels.

A variety of data suggest that Asf1 is also important for coupling histone deposition to DNA synthesis. In budding yeast, asf $1 \Delta$ cells, unlike cells lacking CAF-1, are hypersensitive to the replication inhibitor hydroxyurea (HU) (Le et al. 1997; Tyler et al. 1999; Emili et al. 2001; Hu et al. 2001). Reentry into the cell cycle after HU arrest is poor in cells lacking Asf1 (Tyler et al. 1999), suggesting the presence of irreversible damage on replication fork arrest when Asf1 is absent. Asf1 physically interacts with the DNA damage and $\mathrm{S}$ phase checkpoint kinase, Rad53 (Emili et al. 2001; Hu et al. 2001; Daganzo et al. 2003; Schwartz et al. 2003). Additionally, deletion of ASF 1 causes synthetic growth phenotypes in combination with mutations in a number of genes implicated in DNA replication. These include SGS1, encoding a RecQ-family helicase required for maintaining stalled replication fork integrity (Tong et al. 2001; Cobb et al. 2003), TOP1, encoding DNA topoisomerase 1 , and $C D C 45$, encoding a replication initiation and elongation factor (Tercero et al. 2000; Tong et al. 2004). Finally, deletion of ASF1 increases the frequency of gross chromosomal rearrangements (Myung et al. 2003), a common phenotype for cells with DNA replication defects, causes a modest increase in plasmid loss rates that could be indicative of DNA replication or chromosome segregation defects (Le et al. 1997) and also results in increased rates of sister-chromatid exchanges (Prado et al. 2004). Together, these data suggest that Asf1 helps to actively couple histone deposition and DNA replication. 


\section{CONCLUSIONS}

Histones are deposited onto DNA during DNA synthesis and at other times; some histone chaperones likely function in both pathways. Mounting evidence suggests that DNA replication and RNA transcription occur at discrete sites within the nucleus and are accomplished by large macromolecular machines that coordinate the multiple tasks necessary to complete these complex processes (for review, see Cook 1999). We are just beginning to uncover mechanisms that target histone chaperones to sites of DNA or RNA synthesis. One example of such a targeting mechanism is the interaction between the replicationcoupled histone deposition complex CAF-1 and the DNA polymerase processivity protein PCNA (Shibahara and Stillman 1999; Krawitz et al. 2002). However, genetic data in yeast suggest that other pathways exist to target histone chaperones, like Asf1, to sites of DNA synthesis (Sharp et al. 2001; Krawitz et al. 2002). Much remains to be discovered about the molecular mechanisms that couple histone deposition to DNA metabolic processes.

Additionally, recent work demonstrates that concomitant histone deposition and DNA replication are essential for $S$ phase progression in human cells (Hoek and Stillman 2003; Ye et al. 2003), raising the possibility that cells possess mechanisms for monitoring histone deposition during DNA replication. Understanding this chromatin surveillance and the replication fork defects that occur in the absence of histone deposition will be important contributions to our comprehension of genome stability.

\section{ACKNOWLEDGMENTS}

We thank Erin Green for comments on the manuscript. This work was supported by NIH grant GM55712, NSF grant MCB-0234014, and Department of Energy Field Work Proposal KP110301, and by Department of Energy funds administered through the Lawrence Berkeley National Laboratory. A.A.F. was supported by an NSF predoctoral training grant and an NIH predoctoral training grant.

\section{REFERENCES}

Ahmad K. and Henikoff S. 2002. The histone variant H3.3 marks active chromatin by replication-independent nucleosome assembly. Mol. Cell 9: 1191.

Ai X. and Parthun M.R. 2004. The nuclear Hat1p/Hat2p complex: A molecular link between type B histone acetyltransferases and chromatin assembly. Mol. Cell 14: 195.

Baxevanis A.D. and Landsman D. 1998. Histone sequence database: New histone fold family members. Nucleic Acids Res. 26: 372 .

Belotserkovskaya R., Oh S., Bondarenko V.A., Orphanides G., Studitsky V.M., and Reinberg D. 2003. FACT facilitates transcription-dependent nucleosome alteration. Science 301: 1090.

Blackwell C., Martin K.A., Greenall A., Pidoux A., Allshire R.C., and Whitehall S.K. 2004. The Schizosaccharomyces pombe HIRA-like protein Hip1 is required for the periodic expression of histone genes and contributes to the function of complex centromeres. Mol. Cell. Biol. 24: 4309.

Brill S.J. and Stillman B. 1989. Yeast replication factor-A functions in the unwinding of the SV40 origin of DNA replication. Nature 342: 92.
Cobb J.A., Bjergbaek L., Shimada K., Frei C., and Gasser S.M. 2003. DNA polymerase stabilization at stalled replication forks requires $\mathrm{Mec} 1$ and the RecQ helicase $\operatorname{Sgs} 1$. EMBO J. 22: 4325 .

Cook P.R. 1999. The organization of replication and transcription. Science 284: 1790.

Daganzo S.M., Erzberger J.P., Lam W.M., Skordalakes E., Zhang R., Franco A.A., Brill S.J., Adams P.D., Berger J.M., and Kaufman P.D. 2003. Structure and function of the conserved core of histone deposition protein Asfl. Curr. Biol. 13: 2148.

Eickbush T.H. and Moudrianakis E.N. 1978. The histone core complex: An octamer assembled by two sets of protein-protein interactions. Biochemistry 17: 4955.

Emili A., Schieltz D.M., Yates J.R., III, and Hartwell L.H. 2001. Dynamic interaction of DNA damage checkpoint protein Rad53 with chromatin assembly factor Asf1. Mol. Cell 7: 13.

Enomoto S., Berman J., McCune-Zierath P.D., Gerami-Nejad M., and Sanders M.A. 1998. Chromatin assembly factor I contributes to the maintenance, but not the re-establishment, of silencing at the yeast silent mating loci. Genes Dev. 12: 219.

Enomoto S., McCune-Zierath P.D., Gerami-Nejad M., Sanders M.A., and Berman J. 1997. RLF2, a subunit of yeast chromatin assembly factor-I, is required for telomeric chromatin function in vivo. Genes Dev. 11: 358.

Fanning E. and Knippers R. 1992. Structure and function of simian virus 40 large tumor antigen. Annu. Rev. Biochem. 61: 55

Formosa T. 2003. Changing the DNA landscape: Putting a SPN on chromatin. Curr. Top. Microbiol. Immunol. 274: 171.

Formosa T., Ruone S., Adams M.D., Olsen A.E., Eriksson P., Yu Y., Rhoades A.R., Kaufman P.D., and Stillman D.J. 2002. Defects in SPT16 or POB3 (yFACT) in Saccharomyces cerevisiae cause dependence on the Hir/Hpc pathway: Polymerase passage may degrade chromatin structure. Genetics 162: 1557.

Franklin S.G. and Zweidler A. 1977. Non-allelic variants of histones 2a, 2b and 3 in mammals. Nature 266: 273.

Green C.M. and Almouzni G. 2003. Local action of the chromatin assembly factor CAF-1 at sites of nucleotide excision repair in vivo. $E M B O J$. 22: 5163.

Grewal S.I. and Moazed D. 2003. Heterochromatin and epigenetic control of gene expression. Science 301: 798 .

Gruss C., Wu J., Koller T., and Sogo J.M. 1993. Disruption of the nucleosomes at the replication fork. EMBO J. 12: 4533.

Gunjan A. and Verreault A. 2003. A Rad53 kinase-dependent surveillance mechanism that regulates histone protein levels in S. cerevisiae. Cell 115: 537.

Han M., Chang M., Kim U.J., and Grunstein M. 1987. Histone H2B repression causes cell-cycle-specific arrest in yeast: Effects on chromosomal segregation, replication, and transcription. Cell 48: 589.

Hoek M. and Stillman B. 2003. Chromatin assembly factor 1 is essential and couples chromatin assembly to DNA replication in vivo. Proc. Natl. Acad. Sci. 100: 12183.

Hu F., Alcasabas A.A., and Elledge S.J. 2001. Asf1 links Rad53 to control of chromatin assembly. Genes Dev. 15: 1061.

Jackson V. 1987. Deposition of newly synthesized histones: New histones H2A and H2B do not deposit in the same nucleosome with new histones H3 and H4. Biochemistry 26: 2315.

. 1990. In vivo studies on the dynamics of histone-DNA interaction: Evidence for nucleosome dissolution during replication and transcription and a low level of dissolution independent of both. Biochemistry 29: 719.

Jackson V., Shires A., Tanphaichitr N., and Chalkley R. 1976. Modifications to histones immediately after synthesis. J. Mol. Biol. 104: 471 .

Jenuwein T. and Allis C.D. 2001. Translating the histone code. Science 293: 1074.

Jeruzalmi D., O’Donnell M., and Kuriyan J. 2002. Clamp loaders and sliding clamps. Curr. Opin. Struct. Biol. 12: 217.

Kamakaka R.T., Bulger M., Kaufman P.D., Stillman B., and 
Kadonaga J.T. 1996. Postreplicative chromatin assembly by Drosophila and human chromatin assembly factor 1 . Mol. Cell. Biol. 16: 810.

Kaufman P.D. and Almouzni G. 2000. DNA replication, nucleotide excision repair, and nucleosome assembly. In Chromatin structure and gene expression (ed. S.C.R. Elgin and J.L. Workman), p. 24. Oxford University Press, Oxford, United Kingdom.

Kaufman P.D., Cohen J.L., and Osley M.A. 1998. Hir proteins are required for position-dependent gene silencing in Saccharomyces cerevisiae in the absence of chromatin assembly factor I. Mol. Cell. Biol. 18: 4793.

Kaufman P.D., Kobayashi R., and Stillman B. 1997. Ultraviolet radiation sensitivity and reduction of telomeric silencing in Saccharomyces cerevisiae cells lacking chromatin assembly factor-I. Genes Dev. 11: 345.

Kaufman P.D., Kobayashi R., Kessler N., and Stillman B. 1995. The p150 and p60 subunits of chromatin assembly factor I: A molecular link between newly synthesized histones and DNA replication. Cell 81: 1105.

Kaya H., Shibahara K.I., Taoka K.I., Iwabuchi M., Stillman B., and Araki T. 2001. FASCIATA genes for chromatin assembly factor-1 in Arabidopsis maintain the cellular organization of apical meristems. Cell 104: 131.

Kim U.J., Han M., Kayne P., and Grunstein M. 1988. Effects of histone $\mathrm{H} 4$ depletion on the cell cycle and transcription of Saccharomyces cerevisiae. EMBO J. 7: 2211.

Kornberg R.D. and Thomas J.O. 1974. Chromatin structure; oligomers of the histones. Science 184: 865.

Krawitz D.C., Kama T., and Kaufman P.D. 2002. Chromatin assembly factor I mutants defective for PCNA binding require Asf1/Hir proteins for silencing. Mol. Cell. Biol. 22: 614 .

Krude T. 1995. Chromatin assembly factor 1 (CAF-1) colocalizes with replication foci in HeLa cell nuclei. Exp. Cell Res. 220: 304.

Le S., Davis C., Konopka J.B., and Sternglanz R. 1997. Two new S-phase-specific genes from Saccharomyces cerevisiae. Yeast 13: 1029.

Luger K., Mader A.W., Richmond R.K., Sargent D.F., and Richmond T.J. 1997. Crystal structure of the nucleosome core particle at 2.8 Å resolution. Nature 389: 251.

Maga G. and Hubscher U. 2003. Proliferating cell nuclear antigen (PCNA): A dancer with many partners. J. Cell Sci. 116: 3051 .

Melcher M., Schmid M., Aagaard L., Selenko P., Laible G., and Jenuwein T. 2000. Structure-function analysis of SUV39H1 reveals a dominant role in heterochromatin organization, chromosome segregation, and mitotic progression. Mol. Cell. Biol. 20: 3728.

Mello J.A., Sillje H.H., Roche D.M., Kirschner D.B., Nigg E.A., and Almouzni G. 2002. Human Asf1 and CAF-1 interact and synergize in a repair-coupled nucleosome assembly pathway. EMBO Rep. 3: 329.

Monson E.K., de Bruin D., and Zakian V.A. 1997. The yeast Cac1 protein is required for the stable inheritance of transcriptionally repressed chromatin at telomeres. Proc. Natl. Acad. Sci. 94: 13081.

Murakami Y., Eki T., and Hurwitz J. 1992. Studies on the initiation of simian virus 40 replication in vitro: RNA primer synthesis and its elongation. Proc. Natl. Acad. Sci. 89: 952.

Myung K., Pennaneach V., Kats E.S., and Kolodner R.D. 2003. Saccharomyces cerevisiae chromatin-assembly factors that act during DNA replication function in the maintenance of genome stability. Proc. Natl. Acad. Sci. 100: 6640.

Nabatiyan A. and Krude T. 2004. Silencing of chromatin assembly factor 1 in human cells leads to cell death and loss of chromatin assembly during DNA synthesis. Mol. Cell. Biol. 24: 2853.

Nelson D.M., Ye X., Hall C., Santos H., Ma T., Kao G.D., Yen T.J., Harper J.W., and Adams P.D. 2002. Coupling of DNA synthesis and histone synthesis in S phase independent of cyclin/cdk2 activity. Mol. Cell. Biol. 22: 7459.

Orphanides G., LeRoy G., Chang C.H., Luse D.S., and Reinberg D. 1998. FACT, a factor that facilitates transcript elongation through nucleosomes. Cell 92: 105.

Osley M.A. and Lycan D. 1987. Trans-acting regulatory mutations that alter transcription of Saccharomyces cerevisiae histone genes. Mol. Cell. Biol. 7: 4204.

Poveda A., Pamblanco M., Tafrov S., Tordera V., Sternglanz R., and Sendra R. 2004. Hif1 is a component of yeast histone acetyltransferase B, a complex mainly localized in the nucleus. J. Biol. Chem. 279: 16033.

Prado F., Cortes-Ledesma F., and Aguilera A. 2004. The absence of the yeast chromatin assembly factor Asf1 increases genomic instability and sister chromatid exchange. $E M B O$ Rep. 5: 497.

Quivy J.P., Grandi P., and Almouzni G. 2001. Dimerization of the largest subunit of chromatin assembly factor 1: Importance in vitro and during Xenopus early development. EMBO J. 20: 2015.

Ray-Gallet D., Quivy J.P., Scamps C., Martini E.M., Lipinski M., and Almouzni G. 2002. HIRA is critical for a nucleosome assembly pathway independent of DNA synthesis. Mol. Cell. 9: 1091

Richards E.J. and Elgin S.C. 2002. Epigenetic codes for heterochromatin formation and silencing: Rounding up the usual suspects. Cell 108: 489.

Ruiz-Carrillo A., Wangh L.J., and Allfrey V.G. 1975. Processing of newly synthesized histone molecules. Science 190: 117.

Saunders A., Werner J., Andrulis E.D., Nakayama T., Hirose S., Reinberg D., and Lis J. T. 2003. Tracking FACT and the RNA polymerase II elongation complex through chromatin in vivo. Science 301: 1094.

Schwartz M.F., Lee S., Duong J.K., Eminaga S., and Stern D.F. 2003. FHA domain-mediated DNA checkpoint regulation of Rad53. Cell Cycle 2: 384.

Sharp J.A., Fouts E.T., Krawitz D.C., and Kaufman P.D. 2001. Yeast histone deposition protein Asflp requires Hir proteins and PCNA for heterochromatic silencing. Curr. Biol. 11: 463.

Sharp J.A., Franco A.A., Osley M.A., and Kaufman P.D. 2002. Chromatin assembly factor I and Hir proteins contribute to building functional kinetochores in S. cerevisiae. Genes Dev. 16: 85 .

Shibahara K. and Stillman B. 1999. Replication-dependent marking of DNA by PCNA facilitates CAF-1-coupled inheritance of chromatin. Cell 96: 575 .

Shibahara K., Verreault A., and Stillman B. 2000. The N-terminal domains of histones $\mathrm{H} 3$ and $\mathrm{H} 4$ are not necessary for chromatin assembly factor-1-mediated nucleosome assembly onto replicated DNA in vitro. Proc. Natl. Acad. Sci. 97: 7766.

Smith S. and Stillman B. 1989. Purification and characterization of CAF-I, a human cell factor required for chromatin assembly during DNA replication in vitro. Cell 58: 15 .

. 1991. Stepwise assembly of chromatin during DNA replication in vitro. EMBO J. 10: 971.

Sogo J.M., Stahl H., Koller T., and Knippers R. 1986. Structure of replicating simian virus 40 minichromosomes. The replication fork, core histone segregation and terminal structures. $J$. Mol. Biol. 189: 189.

Sutton A., Bucaria J., Osley M.A., and Sternglanz R. 2001. Yeast Asf1 protein is required for cell cycle regulation of histone gene transcription. Genetics 158: 587.

Tagami H., Ray-Gallet D., Almouzni G., and Nakatani Y. 2004. Histone H3.1 and H3.3 complexes mediate nucleosome assembly pathways dependent or independent of DNA synthesis. Cell 116: 51.

Takeda S., Tadele Z., Hofmann I., Probst A.V., Angelis K.J., Kaya H., Araki T., Mengiste T., Scheid O.M., Shibahara K.-I., Scheel D., and Paszkowski J. 2004. BRU1, a novel link between responses to DNA damage and epigenetic gene silencing in Arabidopsis. Genes Dev. 18: 782.

Tchenio T., Casella J.F., and Heidmann T. 2001. A truncated form of the human CAF-1 p150 subunit impairs the maintenance of transcriptional gene silencing in mammalian cells. Mol. Cell. Biol. 21: 1953.

Tercero J.A., Labib K., and Diffley J.F. 2000. DNA synthesis at individual replication forks requires the essential initiation factor Cdc45p. EMBO J. 19: 2082. 
Tercero J.A., Longhese M.P., and Diffley J.F. 2003. A central role for DNA replication forks in checkpoint activation and response. Mol. Cell 11: 1323.

Tong A.H., Evangelista M., Parsons A.B., Xu H., Bader G.D., Page N., Robinson M., Raghibizadeh S., Hogue C.W., Bussey H., Andrews B., Tyers M., and Boone C. 2001. Systematic genetic analysis with ordered arrays of yeast deletion mutants. Science 294: 2364.

Tong A.H., Lesage G., Bader G.D., Ding H., Xu H., Xin X., Young J., Berriz G.F., Brost R.L., Chang M., Chen Y., Cheng X., Chua G., Friesen H., Goldberg D.S., Haynes J., Humphries C., He G., Hussein S., Ke L., Krogan N., Li Z., Levinson J.N., Lu H., Menard P., Munyana C., Parsons A.B., Ryan O., Tonikian R., Roberts T., Sdicu A.M., Shapiro J., Sheikh B., Suter B., Wong S.L., Zhang L.V., Zhu H., Burd C.G., Munro S., Sander C., Rine J., Greenblatt J., Peter M., Bretscher A., Bell G., Roth F.P., Brown G.W., Andrews B., Bussey H., and Boone C. 2004. Global mapping of the yeast genetic interaction network. Science 303: 808.

Tsurimoto T. and Stillman B. 1991. Replication factors required for SV40 DNA replication in vitro. II. Switching of DNA polymerase alpha and delta during initiation of leading and lagging strand synthesis. J. Biol. Chem. 266: 1961.

Tyler J.K., Adams C.R., Chen S.R., Kobayashi R., Kamakaka R.T., and Kadonaga J.T. 1999. The RCAF complex mediates chromatin assembly during DNA replication and repair. $\mathrm{Na}$ ture 402: 555.

Tyler J.K., Collins K.A., Prasad-Sinha J., Amiott E., Bulger M., Harte P.J., Kobayashi R., and Kadonaga J.T. 2001. Interaction between the Drosophila CAF-1 and Asf1 chromatin assembly factors. Mol. Cell. Biol. 21: 6574.

Verreault A. 2000. De novo nucleosome assembly: New pieces in an old puzzle. Genes Dev. 14: 1430

Verreault A., Kaufman P.D., Kobayashi R., and Stillman B. 1996. Nucleosome assembly by a complex of CAF-1 and acetylated histones H3/H4. Cell 87: 95.

Waga S. and Stillman B. 1998. The DNA replication fork in eukaryotic cells. Annu. Rev. Biochem. 67: 721.

Waga S., Bauer G., and Stillman B. 1994. Reconstitution of complete SV40 DNA replication with purified replication factors. J. Biol. Chem. 269: 10923.

Warbrick E. 2000. The puzzle of PCNA's many partners. Bioessays 22: 997.

Wittmeyer J., Joss L., and Formosa T. 1999. Spt16 and Pob3 of Saccharomyces cerevisiae form an essential, abundant heterodimer that is nuclear, chromatin-associated, and copurifies with DNA polymerase alpha. Biochemistry 38: 8961.

Worcel A., Han S., and Wong M.L. 1978. Assembly of newly replicated chromatin. Cell 15: 969.

Xu H., Kim U.J., Schuster T., and Grunstein M. 1992. Identification of a new set of cell cycle-regulatory genes that regulate S-phase transcription of histone genes in Saccharomyces cerevisiae. Mol. Cell. Biol. 12: 5249.

Ye X., Franco A.A., Santos H., Nelson D.M., Kaufman P.D., and Adams P.D. 2003. Defective S phase chromatin assembly causes DNA damage, activation of the S phase checkpoint, and S phase arrest. Mol. Cell 11: 341.

Yuzhakov A., Kelman Z., Hurwitz J., and O’Donnell M. 1999. Multiple competition reactions for RPA order the assembly of the DNA polymerase delta holoenzyme. EMBO J. 18: 6189.

Zhang Z., Shibahara K., and Stillman B. 2000. PCNA connects DNA replication to epigenetic inheritance in yeast. Nature 408: 221 . 


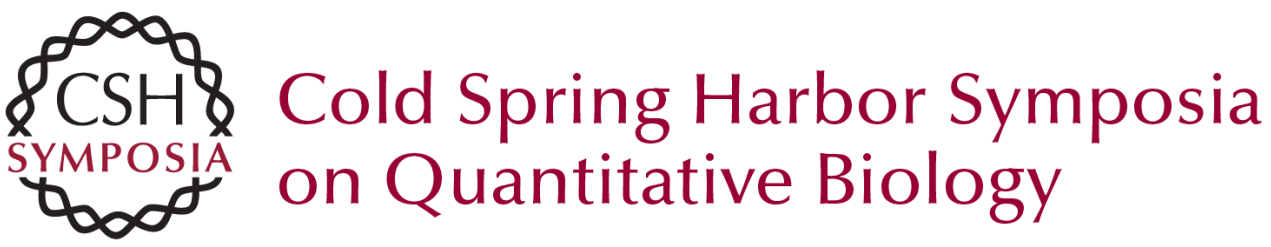

\title{
Histone Deposition Proteins: Links between the DNA Replication Machinery and Epigenetic Gene Silencing
}

\author{
A.A. FRANCO and P.D. KAUFMAN \\ Cold Spring Harb Symp Quant Biol 2004 69: 201-208 \\ Access the most recent version at doi:10.1101/sqb.2004.69.201
}

References This article cites 87 articles, 45 of which can be accessed free at: http://symposium.cshlp.org/content/69/201.full.html\#ref-list-1

\section{License}

Email Alerting

Receive free email alerts when new articles cite this article - sign up in Service the box at the top right corner of the article or click here. 